\title{
The effect of molding pressure on the mechanical properties of CFRTP using paper-type intermediate material
}

\author{
K. Tanaka, T. Yamada, K. Moriito \& T. Katayama \\ Department of Biomedical Engineering, Doshisha University, Japan
}

\begin{abstract}
The press molded parts using the stampable sheets of CFRTP (carbon fiber reinforced thermoplastics) chopped materials have high strength because they can keep a longer fiber length than the injection molding method. Although the mechanical properties of molded parts using stampable sheets are lower than those of continuous fiber reinforced composite materials, they have higher shape flexibility. However, in the stampable sheets of randomly oriented chopped materials, it has been reported that the ends of their fiber bundles can be the initiation of the fracture. Therefore, to reduce the end effect of their fiber bundles, the use of paper-type intermediate material, of which reinforcing fibers are dispersed as individual single fibers, is expected to be used for intermediate materials. In paper-type intermediate materials, reinforcing fibers and matrix resin fibers are dispersed by the paper-making method. Since reinforcing fibers which are placed randomly are crossed densely, high molding pressure is required for production of these material. However, the effect of the molding pressure on the mechanical properties of the molded parts has not been clarified yet. In this study, CFRTP using paper-type intermediate materials were molded at different molding pressures and the effects of the molding pressure on their mechanical and surface properties were evaluated. While it is possible to reduce the voids by using high molding pressure, lower mechanical properties are obtained at the molding pressure of more than $15 \mathrm{MPa}$ due to the breakages of reinforcing fibers during the molding process.

Keywords: thermoplastic composites, carbon fiber, polyamide 6, paper-type intermediate material, chopped materials.
\end{abstract}




\section{Introduction}

In the automobile industry, carbon fiber reinforced thermoplastics (CFRTP) are expected to be used because of their superior properties such as high toughness, high productivity and recycling efficiency $[1,2]$. For forming methods of fiberreinforced composite materials such as CFRTP, the following two methods are employed when discontinuous fibers are used for reinforcing fibers: one is the "injection molding method" where short fibers or long fibers are used, and the other is the "press molding method" where stampable sheets of randomly oriented chopped materials are used. The molded parts using the stampable sheets have high strength because they can keep a longer fiber length than the injection molding method [3]. Although the mechanical properties of molded parts using stampable sheets are lower than those of the continuous fiber reinforced composite materials, they have higher shape flexibility [4]. In the stampable sheets of randomly oriented chopped materials, however, it has been reported that the ends of their fiber bundles can be the initiation of the fracture [5]. Therefore, to reduce the end effect of their fiber bundles, the use of the paper-type intermediate material, of which reinforcing fibers are dispersed as individual single fibers, is expected to be used for intermediate materials [6,7]. In the paper-type intermediate materials, reinforcing fibers and matrix resin fibers are dispersed by the paper-making method [8]. Since reinforcing fibers which are placed randomly are crossed densely, high molding pressure is required for production of these material [9]. However, the effect of the molding pressure on the mechanical properties of the molded parts has not been clarified yet. In this study, CFRTP using paper-type intermediate materials were molded at different molding pressures and the effects of the molding pressure on their mechanical and surface properties were evaluated.

\section{Materials and experimental procedures}

\subsection{Material and molding}

Paper-type intermediate material $\left(\mathrm{V}_{\mathrm{f}}=35 \%\right)$ of carbon fibers and polyamide 6 (PA 6) resin fibers, and UD-tape (Ten Cate, TC910, $\mathrm{V}_{\mathrm{f}}=55 \%$ ) using PA6 for matrix were used in this study. The hot-press molding machine was used for molding, with the molding conditions as shown in Table 1. The specimen which

Table 1: Molding conditions.

\begin{tabular}{ccccc}
\hline Specimen & $\begin{array}{c}\text { Pressure } \\
{[\mathrm{MPa}]}\end{array}$ & $\begin{array}{c}\text { Temperature } \\
{\left[{ }^{\circ} \mathrm{C}\right]}\end{array}$ & $\begin{array}{c}\text { Holding time } \\
{[\mathrm{min}]}\end{array}$ & $\begin{array}{c}\text { Thickness } \\
{[\mathrm{mm}]}\end{array}$ \\
\cline { 1 - 2 } P-5 & 5 & & & \\
\cline { 1 - 2 } P-10 & 10 & 260 & 2 & 2 \\
\cline { 1 - 2 } P-15 & 15 & & & \\
\hline Chop & 6 & & & \\
\hline
\end{tabular}


was molded at molding pressure of $5 \mathrm{MPa}$ is denoted by "P-5". The flow direction of the production line of the paper-type intermediate material is defined as the 0 degree direction as shown in Fig. 1, and CFRTP plates in which 26 layers were laminated by aligning the direction of 0 degrees, were molded as shown in Fig. 2. Chopped materials were cut with width of $10 \mathrm{~mm}$ and length of $15 \mathrm{~mm}$, were laminated randomly, and were molded at molding pressure of $6 \mathrm{MPa}$. The specimen using chopped materials is denoted by "Chop". The surface and the cross section of the molded specimens were observed by the confocal microscope (Laser Tec, OPTILEX H1200).

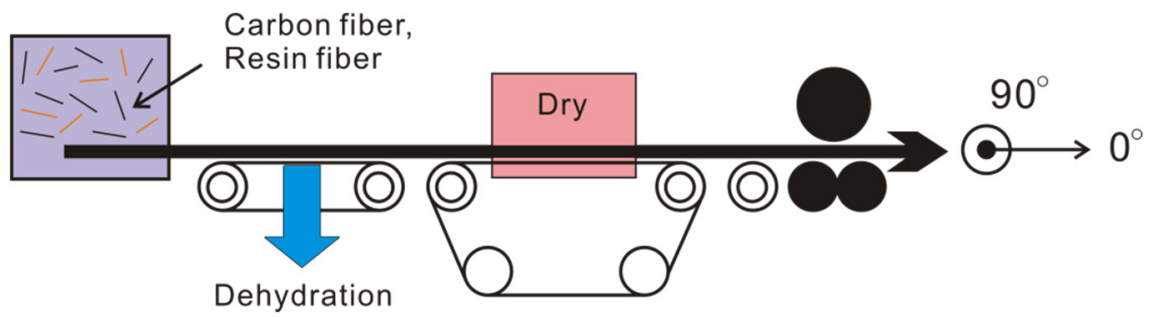

Figure 1: $\quad$ Production line of the paper-type intermediate material.

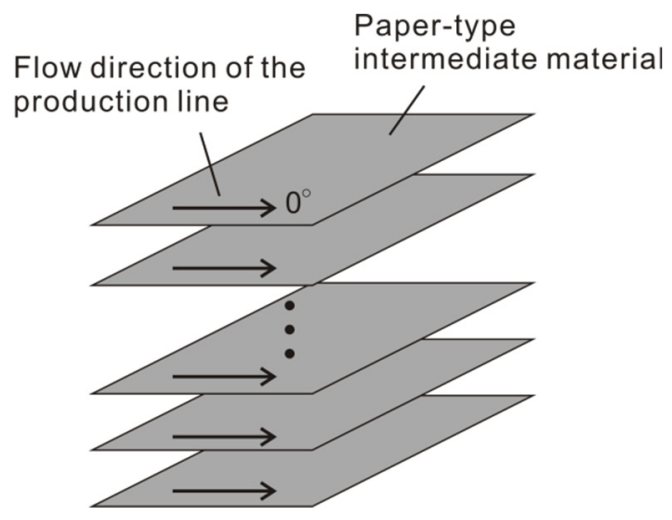

Figure 2: Laminate configuration of CFRTP plates.

\subsection{Measurement of void ratio and fiber length}

The test specimens of $2 \mathrm{~mm} \times 2 \mathrm{~mm} \times 2 \mathrm{~mm}$, which was cut out from the central portion of the CFRTP plates, was observed by a high resolution $3 \mathrm{D}$ X-ray microscope (Rigaku, nano3DX), and the void ratio was measured. After burning off the matrix resin of the specimens with the size of $40 \mathrm{~mm} \times 40 \mathrm{~mm} \times 2 \mathrm{~mm}$ in the electric furnace for 30 minutes at $600^{\circ} \mathrm{C}$, carbon fibers were extracted 
randomly and fiber lengths were measured by using an optical microscope (Leica Microsystem, MZ16).

\subsection{Tensile test}

The specimens which had length of $180 \mathrm{~mm}$, and width of $15 \mathrm{~mm}$ were cut out from the CFRTP plates and tensile tests were conducted for the 0 degree direction and 90 degree direction by using a universal testing machine (Shimadzu Corporation, Autograph AG-100kN) based on JIS-K7164 at the displacement rate of $1 \mathrm{~mm} / \mathrm{min}$. Aluminium tabs which had length of $30 \mathrm{~mm}$, width of $15 \mathrm{~mm}$ and thickness of $1 \mathrm{~mm}$ were glued to both ends of the specimens to reduce stress concentration. The strain distribution of the specimens was measured using a three-dimensional deformation analysis system (GOMmbh, ARAMIS).

\section{Results and discussion}

\subsection{Observation of surface and cross section}

Figure 3 shows the surface of the specimens observed by the confocal microscope. The unimpregnated part can be observed at the molding pressure of $5 \mathrm{MPa}(\mathrm{P}-5)$. Figure 4 shows the cross section of the specimens observed by the confocal microscope. While the voids can be observed at the molding pressure of $5 \mathrm{MPa}$

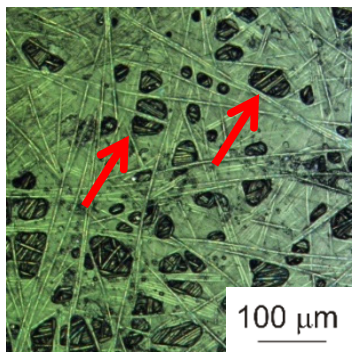

(a) P-5

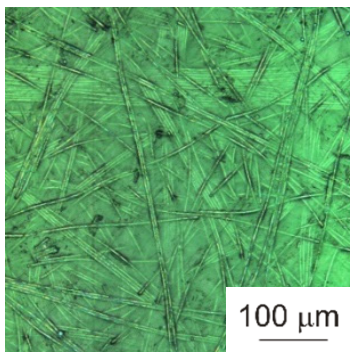

(b) $\mathrm{P}-10$

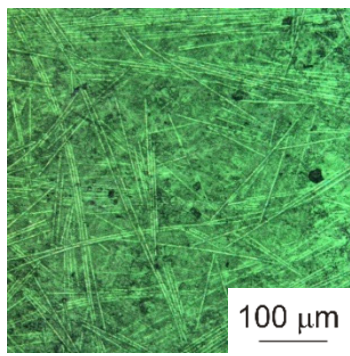

(c) P-15

Figure 3: Surface of specimens.

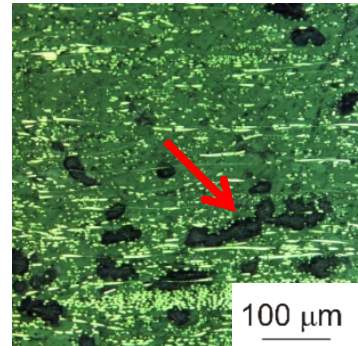

(a) P-5

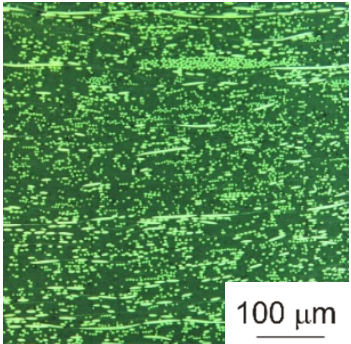

(b) P-10

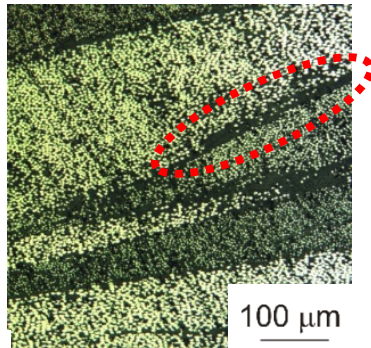

(c) Chop

Figure 4: Cross section of specimens. 
(P-5), almost no voids can be observed in the molding pressure of $10 \mathrm{MPa}(\mathrm{P}-10)$. The resin-rich area can be observed in the specimens using chopped materials (Chop).

\subsection{Measurement of the void ratio and fiber length}

Figure 5 shows the cross section of the specimens at the molding pressure of $15 \mathrm{MPa}$ (P-15) observed by the high resolution 3D X-ray microscope. The breakages of the carbon fibers are observed at the crossed portions of the carbon fibers. Figure 6 shows the relationship between the void ratio of the specimens and molding pressure. The void ratio is high at the molding pressure of $5 \mathrm{MPa}(\mathrm{P}-5)$. Figure 7 shows the carbon fiber length of the specimens. The fiber length becomes shorter as the molding pressure becomes higher. It is considered that the fiber breakages increased more when the molding pressure became higher.

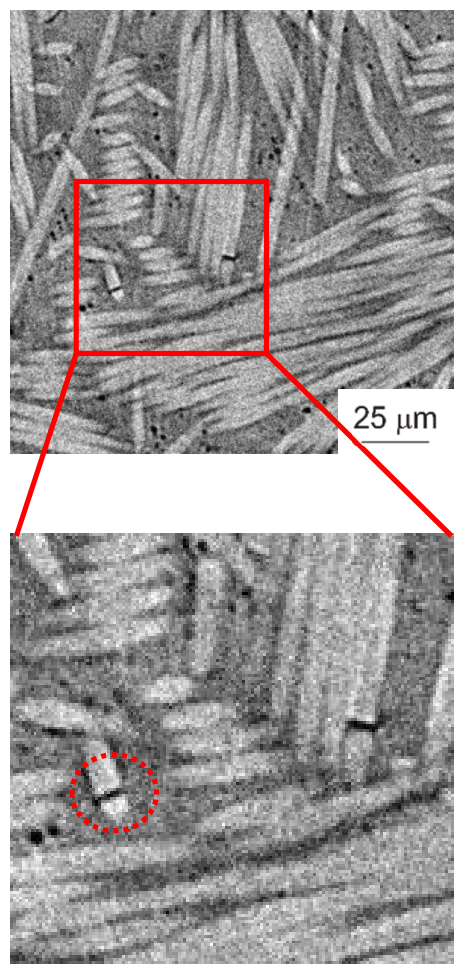

Figure 5: Cross section of specimens (P-15). 
312 High Performance and Optimum Design of Structures and Materials II

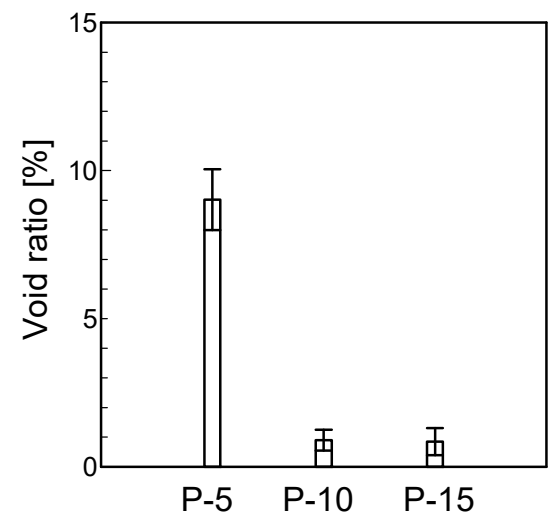

Figure 6: Void ratio of specimens.

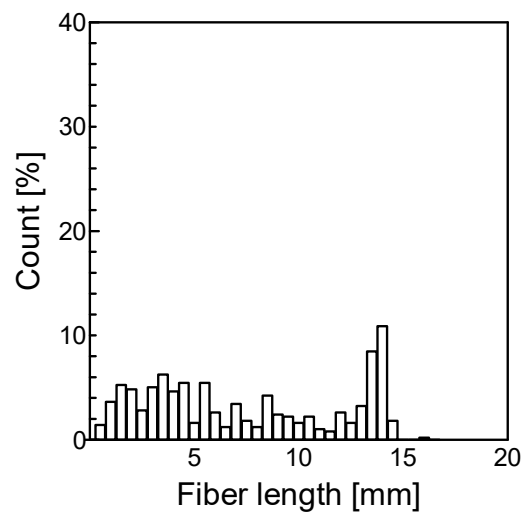

(a) base-material

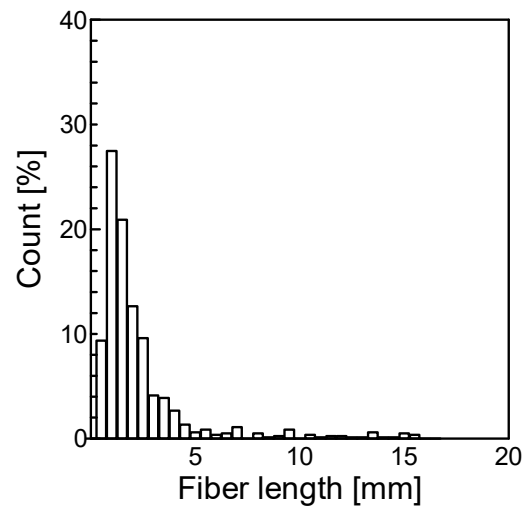

(c) P-10

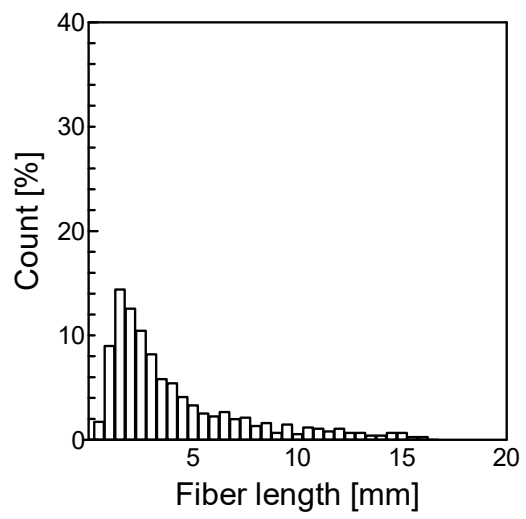

(b) P-5

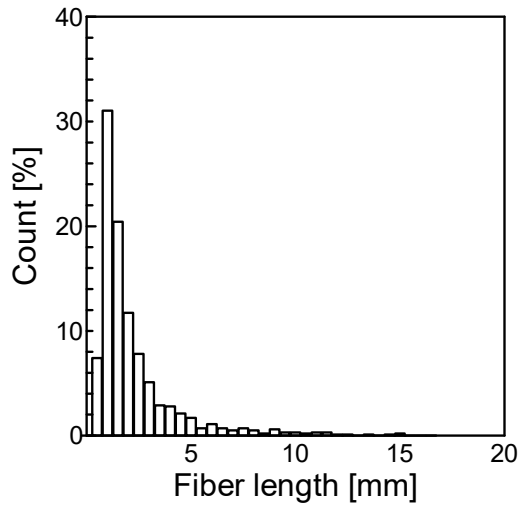

(d) P-15

Figure 7: Fiber length of specimens. 


\subsection{Tensile test}

Figure 8 shows the tensile strength of specimens molded at different molding pressures. The tensile strength of the 90 degree direction is approximately $30 \%$ lower than that of the 0 degree direction. Oriented fiber direction to the 0 degree can be the reason for this difference. Specimens molded at the molding pressure of $10 \mathrm{MPa}(\mathrm{P}-10)$ showed the highest tensile strength. The specimens at the molding pressure of $5 \mathrm{MPa}(\mathrm{P}-5)$ is considered to show smaller tensile strength due to the high void ratio with the unimpregnated part and the specimens at the molding pressure of $15 \mathrm{MPa}(\mathrm{P}-15)$ is considered to show smaller tensile strength due to the shorter tensile strength caused by the breakages during the high pressure molding. Figure 9 shows the strain distribution of the specimens in the tensile tests

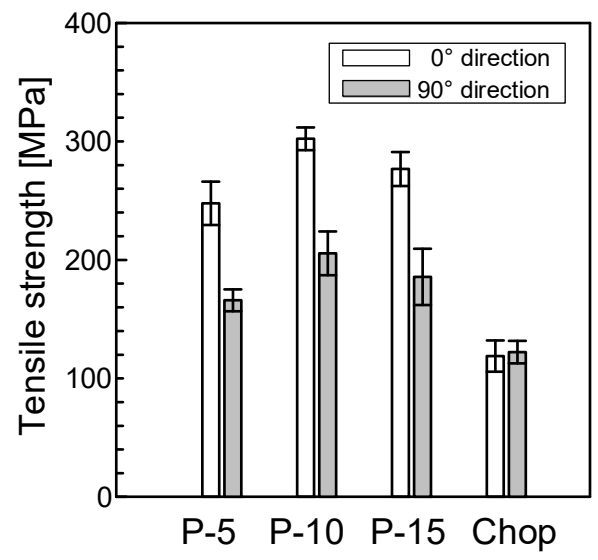

Figure 8: Results of tensile tests.

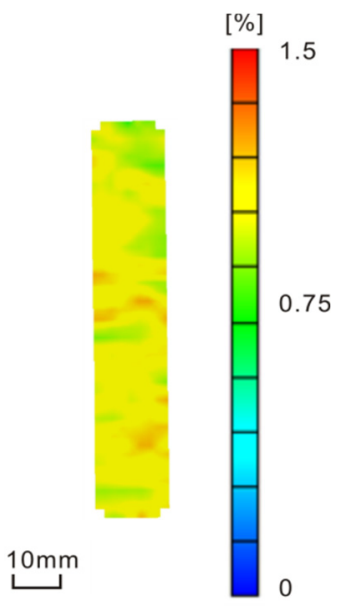

(a) $\mathrm{P}-10$

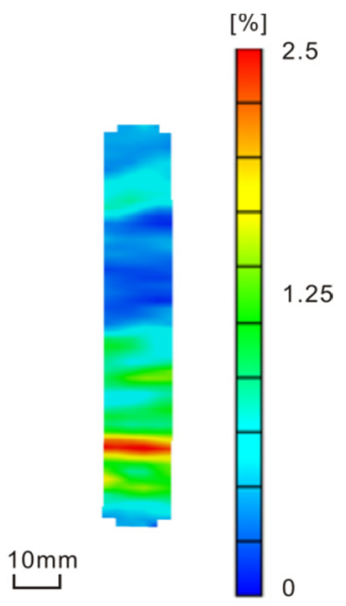

(b) Chop

Figure 9: Strain distribution of tensile specimens. 
just before the final fracture. While the local strain concentration was observed in the specimens using chopped materials (Chop), local strain concentration was not observed in the specimens using paper-type intermediate material (P-10). While the strain concentration point became the initiation of fracture for the chopped materials (Chop), the specimens using paper-type intermediate material and uniform strain and showed a higher tensile strength than the specimens using chopped materials (Chop).

\section{Conclusion}

In this study, CFRTP plates using paper-type intermediate material were molded at different molding pressures, and tensile tests were conducted to clarify the effects of the molding pressure on the mechanical and surface properties of the specimens. The investigation yielded the following conclusions:

1. Specimens molded at the molding pressure of $10 \mathrm{MPa}(\mathrm{P}-10)$ showed the highest tensile strength in the specimens using paper-type intermediate material molded at different molding pressures.

2. While it is possible to reduce the voids by using high molding pressure, lower mechanical properties are obtained at the molding pressure of $15 \mathrm{MPa}$ due to the breakages of reinforcing fibers during the molding process.

3. Specimens using paper-type intermediate material showed a higher tensile strength than the specimens using chopped materials (Chop). This is due to the local strain concentration of the specimens using chopped materials (Chop).

\section{References}

[1] M. Yamane, I. Ohsawa, K. Uzawa, T. Masato and J. Takahashi, "Possibility of repeated recycling of CFRTP for mass production automotive application", Proceedings of 15th European Conference on Composite Materials, pp. 1-8, 2012.

[2] "Composites penetration growth in Automotive: towards mass production 2010-2020 trends and forecasts", JEC Composites, pp. 13-22, 2011.

[3] M. D. Wakeman, T. A. Cain, C. D. Rudd, R. Brooks and A. C. Long, "Compression Moulding of Glass and Polypropylene Composites for Optimised Macro- and Micro-Mechanical Properties", Composites Science and Technology, Vol. 58, pp. 1879-1898, 1998.

[4] M. Yamane, "Technical Collection of Carbon Fiber Reinforced Thermoplastics", Science \& Technology, pp. 34-47, 2015.

[5] Y. Wan and J. Takahashi, "Tensile and compressive properties of chopped carbon fiber tapes reinforced thermoplastics with different fiber lengths and molding pressures", Composites Part A, Vol. 87, pp. 271-281, 2016.

[6] M. Hashimoto, T. Okabe and M. Nishikawa, "Development of Thermoplastic Press Sheet with In-Plane Randomly Oriented and Dispersed Carbon Mono- 
Fibers and Evaluation of the Mechanical Property", Japan Society for Composite Materials, Vol. 37, No. 4, pp. 138-146, 2011.

[7] H. Yu, K. D. Potter and M. R. Wisnom, "A novel manufacturing method for aligned discontinuous fibre composites", Composites Part A, Vol. 65, pp. 175-185, 2014.

[8] H. Ueno and T. Kawamukai, "Sheet for fiber-reinforced plastic molded body", Japan patent JP193731A, 2015.

[9] T. Matoba, "Compound Composite Material-6 Stampable Sheet for Papermaking", Japan Society for Composite Materials, Vol. 19, No. 1, pp. 37, 1993. 